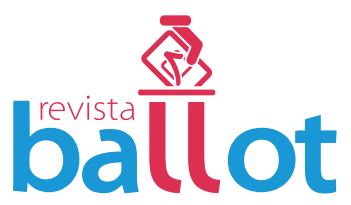

\title{
As mulheres e a política na Alemanha: as cotas de gênero e a democracia interna partidária
}

\author{
Carolina Chagas (UFPR, Brasil)
}

ca.chagas@hotmail.com

Universidade Federal do Paraná

Praça Santos Andrade, 50 - Centro

Curitiba/PR - Brasil - 80020-300 


\title{
Resumo
}

A representação já há tempo tem sido alvo de críticas, podendo ser identificada como uma das causas para esse descontentamento a subrepresentação de alguns estratos da sociedade. Com vias de corrigir esse problema, uma das soluções que se apresenta é a adoção de cotas, estando entre elas as cotas de gênero, as quais visam aumentar a participação de mulheres na política. Existem diversas formas de implementá-las, devendo-se prestar a atenção, sobretudo, na realidade política e social do país em que está inserida, para que consiga proporcionar bons resultados. No Brasil, pelo fato das cotas existentes - as quais na verdade servem para ambos os sexos - recaírem sobre as candidaturas em potencial, há um impacto mínimo em sua aplicação. Há, assim, a necessidade de se estudar outras realidades para tentar extrair o que tem garantido melhores resultados do que o brasileiro. A Alemanha surge, então, como um país em que não só as possibilidades de cotas de gênero tem conquistado êxitos, mas também como um modelo de proteção à democracia intrapartidária. A partir de todo o estudo, concluiu-se, portanto, que apostar nas cotas pode ser um caminho mais rápido e exitoso para fazer as mulheres ascenderem aos cargos públicos, mas que, ao mesmo tempo, também pode significar manter a maior parte do controle de seleção das candidaturas nos partidos políticos, motivo pelo qual a exigência de uma democracia interna se torna ainda maior. Ainda, pôde-se observar que o certo sucesso alemão com as cotas de gênero possui ligação direta ao fomento e proteção dessa democracia intrapartidária no país, podendo, pois, contribuir para melhorar sua efetivação no Brasil.

Palavras-chave: Cotas de gênero - Sistema político alemão - Democracia intrapartidária

\begin{abstract}
The political representation has suffered critics for quite some time, being one of the reasons for this dissatisfaction the subrepresentantion of some social groups. Aiming to solve this problem, one of the presented solutions is the adoption of quotas, like the gender quotas, which attempt to increase women participation in politics. There are a lot of ways to implement they, being important, above all, to pay attention to the political reality in which they are inserted, so that they can produce great results. In Brazil, because the existing quotas that are for both genders - impact only in potential candidacy, their consequences are small. So, there is the need to expend the study of gender quotas in places with better results than the Brazilian's one. Germany emerges not only as a country where the possibilities of gender quotas have conquered some success, but also as a model of protection of the intraparty democracy. From the present study, it is possible to conclude that the quotas can be a faster and successful way to make women ascend in public positions, but, at the same time, they can also maintain most part of the candidature's selections within the political parties, what means a good reason to grow a democratic atmosphere inside the parties. Furthermore, it was observed that the German's success with gender quotas has direct link with this intraparty democracy, whose study can contribute for its practice in Brazil.
\end{abstract}

Keywords: Women Quotas - German Political System - Intraparty democracy 


\section{Introdução}

A tensão existente entre democracia e representatividade há tempos vem sendo estudada, evidenciando insatisfações quanto aos governos no desempenho de suas atividades, sobretudo, em sua (ausência de) responsividade e em sua composição homogênea. ${ }^{1}$ É diante desse recorte da sub-representação que se iniciam as demandas por ações visando a inclusão de grupos sociais minoritários na política, como é o caso das mulheres. De forma a possibilitar um aumento das mulheres nos cargos políticos, muitos países adotaram políticas de cotas de gênero, sendo possível observar diversos resultados, dentre as peculiaridades de cada local. No entanto, vale ressaltar que nem sempre o aumento da participação feminina na política é fruto das cotas legais, uma vez que dentre os países com maiores índices dessa participação, Ruanda (63,8\% de mulheres na Câmara baixa), adota tais cotas, mas Suécia (43,6\% de mulheres em seu Parlamento - Riksdagen), vale-se de políticas afirmativas voluntárias dos partidos. ${ }^{2}$

Nesse sentido, e diante da diversidade em sua aplicação, a adoção de cotas em um sistema político/eleitoral, para além de ser aplicada somente a partir de influências internacionais, deve ser pensada a partir de uma realidade política concreta. Assim, visando proporcionar maiores informações para um possível aprimoramento do estudo das cotas de gênero no Brasil, pretende-se relatar nesse artigo as experiências obtidas na Alemanha sobre a presença das mulheres na política. A Alemanha foi escolhida para a presente pesquisa por, essencialmente, duas razões: não só ela poderá contribuir com os estudos da implementação de cotas de gênero, por realizá-la de maneira diversa da do sistema brasileiro; mas também, tenderá a enriquecer o debate sobre a democracia interna dos partidos políticos, ponto chave para o sucesso de sua política de inclusão, como se verá adiante. No entanto, antes de se iniciar especificamente a análise da realidade alemã, necessário tecer algumas considerações quanto à representatividade e às cotas.

\section{Democracia e representatividade: as cotas de gênero contra a sub-representação}

A representação, em sua teoria, não serviria apenas para tornar possível uma grande república, mas também seria um meio para trazer os diversos conflitos presentes na sociedade para um fórum central único, no qual podem ser controlados e tornados mais inofensivos pelo equilíbrio a ser alcançado. Para alcançar tal equilíbrio, no entanto, necessário seria que os representantes buscassem de fato os interesses dos seus eleitores. ${ }^{3}$ Entretanto, aos poucos foi se observando que as instituições representativas, projetadas precipuamente para abrir o do-

1. MIGUEL, Luís Felipe. Impasses da Accountability: dilemas e alternativas da representação política. In: Revista Sociologia Política, Cuririba, n. 25, jun 2006, p. 165-178.

2. INTER-PARLIAMENTARY UNION. Women in national parliaments. Disponível em: < http:// www.ipu.org/wmn-e/classif.htm>. Acesso em: 30 ago 2015.

3. PITKIN, Hanna Fenichel. Representação: Palavras, Instituições e Ideias. Disponível em: < http://www. scielo.br/pdf/ln/n67/a03n67.pdf>. Acesso em: 10 mai 2015, p. 37. 
mínio público para o povo comum anteriormente excluído, vinha servindo, na verdade, para afastá-lo de um verdadeiro envolvimento político. ${ }^{4}$

De uma maneira geral, não há uma busca pela observância dos interesses dos representados, ao mesmo tempo em que uma participação mais direta dessa população também se vê prejudicada, uma vez que a noção de representatividade em sua concepção inicial não foi concebida como uma forma de democracia, ou um regime em que a vontade popular seja posta em situação de governar. ${ }^{5}$ Assim, "a familiaridade com que a expressão 'democracia representativa' é recebida não deve obscurecer o fato de que ela encerra uma contradição", uma vez que se trata de um governo do povo no qual ele não se encontra presente na maioria dos processos de tomada de decisão. ${ }^{6}$ Luís Felipe Miguel apresenta ao menos três problemas presentes nas democracias representativas atuais: (i) as decisóes políticas são tomadas por um pequeno grupo e não pela maioria dos que serão submetidos a elas; (ii) a formação de uma elite política distanciada da massa da população, como consequência da especialização funcional; e (iii) a ruptura do vínculo entre a vontade dos representados e a vontade dos representantes. ${ }^{7}$

Evidencia-se, assim, que o "governo do povo" na verdade se concretiza como o "governo autorizado pelo povo", através de uma instrumentalização da cidadania e da soberania popular. A representação, pois, não se relaciona de forma ideal com a democracia, o que faz surgir, por outro lado, uma contrapartida para que ela seja desempenhada da melhor forma possível, haja vista ainda ser uma forma de governo prevista e necessária nas sociedades modernas, em que as pessoas não conseguem estar presentes em todas as tomadas de decisões que afetam sua vida. ${ }^{8} \mathrm{Uma}$ forma de aprimorá-la é fazer com que ela esteja ligada aos ideais de igualdade e de autodeterminação, visando fomentar o pluralismo político. ${ }^{9}$ Para Robert Post, seria essa autodeterminação essencial para um regime democrático, de maneira que a população ficasse convicta de que está participando no processo de governar a si mesma, enfatizando a importância maior de conseguir reconhecer uma certa decisão como própria, independentemente de se estar realmente tomando particularmente tal decisão. ${ }^{10}$ Tem-se que a representação, então, deve fazer parte de uma democracia inclusiva, capaz de garantir espaços políticos efetivos para concepções de vida não hegemônica, como parte de um pluralismo político, ${ }^{11}$ a fim de dar formas a essa autodeterminação.

4. PITKIN, Hanna Fenichel. Representação: Palavras, Instituições e Ideias, p. 42.

5. MANIN, Bernard. La democracia de los modernos: los principios del gobierno representativo. Disponível em: <http://webcache.googleusercontent.com/search?q=cache:CAYbExB3d9YJ:www. hacienda.go.cr/centro/ datos/Articulo/La\%2520democracia\%2520de\%2520los\%2520modernos. $\mathrm{doc}+\& \mathrm{~cd}=1 \& \mathrm{hl}=\mathrm{fr} \& \mathrm{ct}=\mathrm{clnk} \& \mathrm{gl}=\mathrm{br}>$. Acesso em: 10 mai 2015 .

6. MIGUEL, Luís Felipe. Impasses da Accountabilityః dilemas e alternativas da representação política, p. 166.

7. MIGUEL, Luís Felipe. Impasses da Accountability: dilemas e alternativas da representação política, p. 166.

8. YOUNG, Iris Marion. Inclusion and Democracy. Oxford: Oxford University Press, 2000, p. 124.

9. SALGADO, Eneida Desiree. Representação política e o modelo democrático brasileiro. In: CLÈVE, Clèmerson Merlin (Coord.). Direito Constitucional Brasileiro, vol.1: Teoria da Constituição e Direitos Fundamentais. São Paulo: Revista dos Tribunais, 2014, p. 1089 - 1105, p. 1089.

10. POST, Robert. Democracy and Equality. Disponível em: <http://digitalcommons.law.yale.edu/fss_ papers/177/>. Acesso em: 10 mai 2015, p. 4.

11. SALGADO, Eneida Desiree. Representação política e o modelo democrático brasileiro, p. 1092. 
O problema em conseguir se concretizar essa autodeterminação é que os laços que deveriam ligar os eleitores comuns aos parlamentares se encontram enfraquecidos, motivo pelo qual é cada vez mais comum a busca por alternativas que aproximem representantes dos representados, sendo a previsão de cotas uma delas. Segundo Luís Felipe Miguel, de uma maneira geral, as propostas de cotas seguem ao menos um dos seguintes objetivos: (i) ampliação da representatividade mimética do corpo decisório (tornar governantes mais parecidos com os governados); (ii) ampliação da pluralidade de vozes e perspectivas presentes nas esferas decisórias; (iii) ampliação da força política de grupos tradicionalmente marginalizados; e (iv) ampliação da rotatividade nos cargos decisórios, impedindo a cristalização de uma elite política. ${ }^{12}$

As cotas, portanto, vem para sanar um dos principais problemas identificados na representação que é a sub-representação de determinados grupos sociais, visto que "o grupo dos governantes, em relação ao conjunto da população, tende a ser muito mais masculino, muito mais rico, muito mais instruído e muito mais branco". Não bastaria, assim, somente eliminar as barreiras de inclusão, mas também incorporar explicitamente os grupos marginalizados à política. ${ }^{13}$ De acordo com Iris Young, uma das maiores vantagens de se incorporar esses grupos à política seria a nova perspectiva social que eles incorporariam no Estado. Segundo a filósofa, existiriam três formas com as quais uma pessoa conseguiria se sentir representada: por seus interesses, suas opinióes ou sua perspectiva social. Assim, observa-se que a representação não se remeteria apenas aos objetivos ou valores compartilhados entre representantes e representados, mas também, às diferentes histórias, experiências, conhecimentos sociais que derivam de um determinado grupo social. ${ }^{14}$ Isso não significaria afirmar que tal grupo seja totalmente homogêneo, com integrantes detentores de um pensamento uniforme; contudo, ainda assim haveria a vantagem de se abordar a perspectiva social, no que tange a afinidade que todos compartilhariam ao descreverem acontecimentos e experiências sob pontos-de-vista similares. ${ }^{15}$ Seria esse, pois, um dos grandes interesses na utilização de cotas na política; ou seja, uma forma de inclusão de diversos grupos marginalizados, contando com a participação das suas perspectivas sociais distintas entre os representantes do governo - e isso incluiria o caso das mulheres.

A exclusão das mulheres da política é histórica e perpassa por noções de como deveria ser o papel convencional a ser desempenhado pelo sexo feminino, tido como naturalmente altruísta e dedicado a servir os outros. ${ }^{16} \mathrm{~A}$ predominância masculina nesta seara resultou em uma reivindicação a nível mundial para a criação de políticas que aumentassem a presença das mulheres nos cargos eletivos, tendo sido as cotas utilizadas como forma mais rápida de quebrar essa barreira sexista, de forma a promover mudanças mais profundas no corpo representativo. ${ }^{17}$

12. MIGUEL, Luís Felipe. Impasses da Accountability: dilemas e alternativas da representação política, p. 172.

13. MIGUEL, Luís Felipe. Impasses da Accountability: dilemas e alternativas da representação política, p. 174.

14. YOUNG, Iris Marion. Inclusion and Democracy, p. 134-136.

15. YOUNG, Iris Marion. Inclusion and Democracy, p. 137.

16. BALDEZ, Lisa. The Pros and Cons of Gender Quota Laws: What Happens When You Kick Men Out and Let Women In?. In: Politics \& Gender, 2 (2006), pp. 102-109. Disponível em: < http://dx.doi. org/10.1017/S1743923X06221019>. Acesso em: 31 ago. 2015, p. 105.

17. BALDEZ, Lisa. The Pros and Cons of Gender Quota Laws, p. 104; DAHLERUP, Drude. What are the Effects of Electoral Gender Quotas? From studies of quota discourses to research on quota effects. Disponível em: <http://paperroom.ipsa.org/app/webroot/papers/paper_5301.pdf>. Acesso em: 31 ago. 2015, p. 5 . 
Isso não significa que sua implementação não enfrente resistências por aqueles que acreditam que elas privilegiam muito mais grupos do que indivíduos e acabam com a igualdade de oportunidades. Dentre os principais argumentos contrários às cotas de gênero tem-se que a presença de mais mulheres na política não necessariamente aumentaria a defesa de causas feministas, bem como que sua presença poderia deslegitimar aqueles candidatos e candidatas que conseguem alcançar seus postos sem seu auxílio - ou seja, atacaria a meritocracia. De uma forma geral, no entanto, essas críticas negligenciam as vantagens trazidas pela noção de perspectiva social, aqui já tratada. Fato é que a presença dessas cotas trazem uma mudança na agenda política e na consciência de gênero nesta seara. ${ }^{18}$

Aumentar o número de mulheres na política através das cotas pode ser feito através do estabelecimento de uma porcentagem mínima da representação somente para mulheres, ou uma que preveja máximo-mínimo para ambos os sexos. Essas quotas podem atingir diferentes níveis do processo eleitoral, tanto na seleção de potenciais candidatos, nos candidatos certos que vão concorrer à eleição ou naquelas pessoas que já foram eleitas. Ademais, elas podem ser instituídas de maneira legal, nas Constituições dos países ou em leis eleitorais; ou ainda, serem previstas de forma voluntária pelos partidos políticos. ${ }^{19}$

No Brasil, há presença de cotas eleitorais previstas pela Lei das Eleições (Lei nº 9.504/97), a qual determina que cada partido ou coligação deverá preencher um mínimo de $30 \%$ e um máximo de $70 \%$ para candidaturas de cada sexo. Observa-se, assim, que as cotas não são especificamente para o gênero feminino, por mais que a leitura dada ao artigo normalmente é para que as mulheres recebam a porcentagem mínima das candidaturas. Ressalta-se, ainda, que a possibilidade dos partidos registrarem um numero de candidatos é de até $150 \%$ das vagas previstas, fazendo com que a real porcentagem de mulheres com chances de alcançar um cargo eletivo seja ínfima. ${ }^{20}$ As cotas no Brasil, portanto, são legais e previstas para os candidatos registrados, mas não possuem conotação específica para o gênero feminino, sendo pouco eficazes para aumentar a participação feminina na política. Tendo em vista esse breve panorama brasileiro, passa-se a analisar a realidade alemã como contraste.

18. KROOK, Mona Lena. Gender Quotas, Norms, and Politics. In: Politics \& Gender, 2 (2006), pp. 110-118. Disponível em: < http://dx.doi.org/10.1017/S1743923X06231015>. Acesso em: 31 ago 2015, p. 110/111.

19. DAHLERUP, Drude. What are the Effects of Electoral Gender Quotas? From studies of quota discourses to research on quota effects, p. 6 .

20. Lei no 9.504/97 - Art. 10. Cada partido poderá registrar candidatos para a Câmara dos Deputados, Câmara Legislativa, Assembléias Legislativas e Câmaras Municipais, até cento e cinqüenta por cento do número de lugares a preencher. (...)

$\S 30$ Do número de vagas resultante das regras previstas neste artigo, cada partido ou coligação preencherá o mínimo de 30\% (trinta por cento) e o máximo de 70\% (setenta por cento) para candidaturas de cada sexo. 


\section{Alemanha e a participação das mulheres na política}

A participação das mulheres alemãs na política está entre as vinte melhores do mundo, tendo sido atingido um percentual de 36,5\% nas últimas eleições para seu parlamento (Bundestag) em 2013. ${ }^{21}$ Essa afirmação é resultado de uma preocupação com a participação das mulheres na política que data desde a década de $1970,{ }^{22}$ contudo, isso não significa que os problemas ligados à desigualdade de gênero estejam todos sanados. Assim, antes de se adentrar propriamente na política de cotas adotada na Alemanha, algumas consideraçóes sobre o quadro geral das mulheres na sociedade alemã serão aqui traçadas.

As mulheres já compõem $51 \%$ da população alemã. ${ }^{23}$ Dentre elas, o número de mulheres que terminaram a escola com aptidão para ascender ao ensino superior é de $56 \%$ a mais que o de homens; no entanto, apesar de serem bem qualificadas, suas chances no mercado de trabalho são menores. ${ }^{24}$ Primeiramente, elas continuam ganhando menos que trabalhadores do sexo masculino, desempenhando as mesmas funções, com as mesmas qualificações, havendo uma diferença em média de $21,6 \%$ entre os salários. ${ }^{25}$ Ainda, a presença feminina em posições de chefia continua ínfima, representando $4 \%$ das mulheres no mercado de trabalho - contra $10 \%$ dos homens ${ }^{26}$ Nesse sentido, e visando especificamente alterar esse quadro negativo, em 2015 foi aprovada uma lei que institui cotas femininas para as posições de chefia e gestão em grandes empresas privadas e na administração pública. Será cobrada, assim, uma participação feminina mínima de 30\% a partir do ano de $2016 .{ }^{27}$ Observa-se, então, que as questões de gênero ainda se encontram em pauta na sociedade alemã.

Se as cotas surgiram agora na seara socioeconômica, elas já existem há algum tempo na política. De uma maneira geral, as cotas de gênero na política alemã são de caráter voluntário

21. Já o Brasil se encontra na 116 a posição, com apenas $9,9 \%$ de mulheres na Câmara dos Deputados INTER-PARLIAMENTARY UNION. Women in national parliaments.

22. XYDIAS, Christina. Women's Rights in Germany: Generations and Gender Quotas. In: Politics \& Gender, 10 (2014), 4-32. Disponível em: < http://dx.doi.org/10.1017/S1743923X13000524>. Acesso em: 31 ago 2015, p. 12.

23. Dados colhidos até Julho de 2015 - CIA. The World Fact Book. Disponível em: <https://www.cia. gov/library/publications/resources/the-world-factbook/geos/gm.html>. Acesso em: 28 ago. 2015.

24. HOFMEISTER, Heather; Hünefeld, Lena. Frauen in Führungspositionen. In: BUNDESZENTRALE FÜR POLITISCHE BILDUNG. Dossier: Frauen in Deutschland. Disponível em: < http://www.bpb.de/ gesellschaft/gender/frauen-in-deutschland/49400/fuehrungspositionen>. Acesso em: 28 ago. 2015.

25. BUNDESZENTRALE FÜR POLITISCHE BILDUNG. Frauen auf dem Arbeitsmarkt der EU. Disponível em: < http;//www.bpb.de/politik/hintergrund-aktuell/202187/frauen-auf-dem-arbeitsmarkt>. Acesso em: 28 ago. 2015 - Trata-se de um mau resultado para a Alemanha, tendo em vista que a média da União Europeia seria de 16,4\% de diferença entre os salários, figurando a Eslovênia com a menor taxa (3,2\%).

26. HOFMEISTER, Heather; Hünefeld, Lena. Frauen in Führungspositionen.

27. SPIEGEL ONLINE. Gleichberechtigung: Bundestag beschließt Frauenquote. Disponível em: < http://www.spiegel.de/politik/deutschland/deutscher-bundestag-beschliesst-frauenquote-a-1022093. html>. Acesso em: 28 ago. 2015. 
por parte dos partidos. ${ }^{28}$ Desde o início cabe ressaltar que não são todos os partidos que utilizam essa política afirmativa: CSU (Christlich-Soziale Union in Bayern) - partido presente somente na região da Baviera, mas de extensão federal - e FDP (Freie Demokratische Partei) não estabelecem um número mínimo para a participação feminina, apesar de ambos fazerem menção à importância da participação das mulheres na política intrapartidária em seus programas. ${ }^{29}$

Os demais quatro principais partidos participantes das eleições federais fazem uso de cota. O primeiro a adotar essa medida foi Grüne (“Os Verdes”), que em 1979 instituiu uma cota de $50 \%$ de participação feminina para todos os cargos e mandatos, utilizando-se, para tanto, de uma lista de candidatura alternada entre homens e mulheres. Em seu estatuto, consta que as mulheres devem necessariamente participar das posições ímpares da lista, o que lhes garante o primeiro lugar; no entanto, a elas ainda é reservada a possibilidade de estarem em um lugar par da lista, ou mesmo a realização de listas puramente femininas. No SPD (Sozialdemokratische Partei Deutschlands) há desde 1988 previsão de cotas, as quais foram aumentando, resultando atualmente em um mínimo de $40 \%$ de participação de um dos gêneros, nas listas e posições de comando do partido. Die Linke ("A Esquerda") prevê, também, que a participação das mulheres seja de no mínimo metade nas comissões, diretorias e listas, ressaltando que na impossibilidade das vagas para essa quantidade mínima serem preenchidas, elas devem permanecer em aberto, até que haja mulheres que as preencham, podendo haver novas eleiçóes para tanto a qualquer momento. Por fim, CDU (Christlich Demokratische Union), instituiu, em 1996, a necessidade de participação de pelo menos um terço de mulheres em suas comissões e mandatos públicos, bem como criou-se um quórum mínimo também de um terço nas votações para mulheres. Não sendo atingido esse quórum em uma primeira votação, ela ser anulada; porém, na segunda votação, mesmo que não se atinja o número mínimo de mulheres, haverá validade ${ }^{30}$ Vale ressaltar que antes da implementação dessas cotas, o número de mulheres no parlamento nunca conseguiu ir muito além da porcentagem de $9 \%$ das cadeiras. ${ }^{31}$

Essas políticas afirmativas, com essas peculiaridades, conseguem ser aplicadas e possuem certo sucesso nas eleições alemãs devido ao seu sistema político-partidário. A Alemanha é um país parlamentarista e bicameralista, sendo suas duas câmaras conhecidas como Bundestag e Bundesrat. O Bundesrat seria o conselho federal, composto por 69 membros, os quais são indicados pelos governos regionais de cada uma das 16 regiôes/estados alemãs, sendo que o número de representantes por região varia de 3 a 6 de acordo com a quantidade de

28. Sendo a Alemanha um país federativo, possuindo diversos partidos políticos que podem ser somente de caráter regional, focar-se-á a presente análise somente nos partidos com amplitude federal, mas especificamente nas eleições para o Bundesrat.

29. KÜSCHNER, Isabelle. Frauen in den Parteien. In: APuZ - Aus Politik und Zeitgeschichte. Frauen in Politik und Medien. Disponível em: < http://www.bpb.de/shop/zeitschriften/apuz/31540/frauen-inpolitik-und-medien>. Acesso em: 28 ago. 2015, p. 20.

30. XYDIAS, Christina. Women's Rights in Germany: Generations and Gender Quotas, p. 12; KÜSCHNER, Isabelle. Frauen in den Parteien, p. 20; QUOTA PROJECT. Germany. Disponível em: < http:// www.quotaproject.org/uid/countryview.cfm?id=61>. Acesso em: 28 ago. 2015; ALEMANN, Ulrich von; ERBENTRAUT, Philipp; WALTHER, Jens. Das Parteiensystem der Bundesrepublik Deutschland. Wiesbaden: VS Verlag, 2010, p. 172.

31. HOECKER, Beate. Frauen in der Politik. In: BUNDESZENTRALE FÜR POLITISCHE BILDUNG. Dossier: Frauen in Deutschland. Disponível em: <http://www.bpb.de/gesellschaft/gender/ frauen-in-deutschland/49362/frauen-in-der-politik>. Acesso em: 28 ago. 2015. 
habitantes. ${ }^{32}$ Já a composição do Bundestag é feita por deputados votados diretamente pelo povo; evidencia-se, assim, que esta é a única instituição estatal cuja legitimação deriva diretamente da soberania popular, ${ }^{33}$ ou seja, as eleições federais na Alemanha são somente para essa câmara parlamentar, sendo que o voto não é obrigatório. ${ }^{34}$ Essa votação se dá de forma mista: 299 cadeiras são preenchidas pelo sistema majoritário (regra do candidato mais votado), enquanto o restante deverá ser preenchido através de votação por lista fechada em um sistema proporcional. Cada eleitor possui dois votos, um que será para um candidato específico em um dos distritos eleitorais, e o outro para a lista partidária. São necessários um mínimo de 5\% dos votos no sistema proporcional, ou três cadeiras pelo sistema majoritário, para um partido alcançar as cadeiras destinadas ao sistema proporcional do Bundestag. ${ }^{35}$ Observa-se, portanto, que nesse sistema há uma grande ingerência dos partidos na escolha dos candidatos, o que favorece a prática e aplicação de suas políticas internas e voluntárias de cotas.

Nas últimas eleições para o Bundestag ocorridas em 2013, a maioria das cadeiras ficou com a coalizão do CDU-CSU, que totalizou 311, seguida pelo SPD (193 cadeiras), Die Linke (64 cadeiras) e Grüne (63 cadeiras). ${ }^{36}$ Entre os candidatos votados por partidos, 23,9\% no CDU foram mulheres, $25 \%$ no CSU, 44\% no SPD, 56\% no Die Linke e 55,6\% no Grüne. ${ }^{37}$ Tais resultados evidenciam um maior sucesso das cotas nos partidos de centro-esquerda e esquerda, os quais também são conhecidos pela ênfase nos e defesa dos direitos políticos e econômicos das mulheres - enquanto, de uma maneira geral, os demais partidos possuem uma tendência em focar nos direitos femininos relacionados à família. ${ }^{38}$

Apesar de contar com uma mulher em um dos mais altos cargos do Estado desde 2005 - chanceler Angela Merkel, filiada ao CDU, bem como com uma política de cotas que tem conseguido cada vez mais alçar as mulheres na política (conseguindo elas em alguns casos serem as mais votadas de seu partido), a sociedade alemã ainda se depara com alguns desafios. De um lado, já há estudos que indicam que não só as mulheres provenientes de candidaturas com cotas, mas possivelmente também que alguns homens de seus partidos, têm se sensibilizado cada vez mais com pautas femininas, a partir da discussão que se abre desde o início do processo eleitoral (com as cotas) sobre a importância da participação das mulheres. ${ }^{39}$

32. INTER-PARLIAMENTARY UNION. GERMANY: Bundesrat (Federal Council). Disponível em: <http://www.ipu.org/parline-e/reports/2122_A.htm>. Acesso em: 30 ago. 2015.

33. RUDZIO, Wolfgang. Das politische System der Bundesrepublik Deutschland. Wiesbaden: VS Verlag, 2011, p. 210.

34. Mesmo o voto não sendo obrigatório, houve presença de 71,53\% dos eleitores nas urnas - INSTI-

TUTE FOR DEMOCRACY AND ELECTORAL ASSISTENCE. Voter turnout data for Germany* Disponivel em: < http://www.idea,int/vt/countryview.cfm?CountryCode=DE >. Acesso em: 30 ago. 2015.

35. INTER-PARLIAMENTARY UNION. GERMANY: Deutscher Bundestag (German Bundestag). Disponível em: <http://www.ipu.org/parline-e/reports/2121_A.htm>. Acesso em: 30 ago. 2015.

36. INTER-PARLIAMENTARY UNION. GERMANY: Deutscher Bundestag (German Bundestag),

37. DER BUNDESWAHLLEITER. Gewählte nach Parteien. Disponível em: < http://www.bundeswahlleiter.de/de/bundestagswahlen/BTW_BUND_13/ergebnisse/gewaehlte/partei/>. Acesso em: 28 ago 2015.

38. XYDIAS, Christina. Women's Rights in Germany: Generations and Gender Quotas, p. 26.

39. XYDIAS, Christina. Women's Rights in Germany: Generations and Gender Quotas, p. 19-27. 
Por outro lado, há o reconhecimento e preocupação de que as mulheres na política ainda sofrem com estereótipos negativos na sociedade, o que é, sobretudo, reforçado pela atuação da mídia. ${ }^{40}$

Como mesmo é apontado por Carole Pateman, "tem sido mais fácil concretizar reformas jurídicas e políticas - embora ainda haja um longo caminho a percorrer em termos globais - do que mudanças nas práticas sociais, nas crenças e atitudes e nas concepções de masculinidade e feminilidade" ${ }^{41}$ Ainda resta, portanto, a sensação de que política seria algo essencialmente masculino, e que às mulheres não caberiam características básicas como liderança, racionalidade e autoconfiança para seguir esta carreira. Da mesma forma, tende-se a desconfiar da competência da mulher para exercer determinado cargo, bem como os méritos que a fizeram chegar lá. E, nesta luta não só contra os candidatos masculinos, mas também contra os estereótipos sociais, ela ainda se depara com uma posição dos meios de comunicação mais preocupados com sua vida pessoal, do que com suas propostas e seus objetivos. ${ }^{42}$

A Alemanha, portanto, ainda tem no que avançar quando o assunto é garantir o respeito e observância aos direitos das mulheres, isso não significa que, diante todo esse quadro traçado, não haja o que se aprender com as experiências dessa país. Se as cotas que influenciam no aumento da participação feminina são voluntárias e funcionam em sua maior parte, é porque essa participação já é garantida desde o início do processo eleitoral, dentro dos partidos políticos, o que demonstra verdadeiro desempenho da democracia interna partidária, algo nem sempre previsto em todos os países.

\section{A chave para o sucesso: a democracia interna partidária}

O aumento da participação das mulheres alemãs na política foi fruto de um apelo social, que resultou na implementação de cotas voluntárias pelos principais partidos, ampliando aos poucos a ocupação dos cargos eletivos. Entretanto, essa ampliação não se deu somente nos postos do governo, mas também nas esferas internas e filiação dos partidos. Antes da adoção das cotas e o incentivo à participação feminina, a porcentagem de mulheres filiadas aos partidos não chegava a $25 \%$ em todos eles. Atualmente, esse número aumentou, ficando os partidos Grüne e Die Linke com uma porcentagem próxima dos $38 \%$; SPD com $31 \%$ e CDU ainda na casa dos $25 \%{ }^{43}$

40. MEYER, Birgit. "Nacht, wenn der Generalsekretär weint" - Politikerinnen in der Presse. In: APuZ - Aus Politik und Zeitgeschichte. Frauen in Politik und Medien. Disponível em: < http://www.bpb. de/shop/zeitschriften/apuz/31540/frauen-in-politik-und-medien>. Acesso em: 28 ago. 2015; HOLTZBACHA, Christina. Politikerinnen - Bilder im internationalen Vergleich. In: APuZ - Aus Politik und Zeitgeschichte. Frauen in Politik und Medien. Disponível em: < http://www.bpb.de/shop/zeitschriften/ apuz/31540/frauen-in-politik-und-medien >. Acesso em: 28 ago. 2015.

41. PATEMAN, Carole. Garantir a cidadania das mulheres: A indiferença e outros obstáculos. Tradução de Teresa Tavares. In: Revista Crítica de Ciências Sociais, n. 89, 2010. Disponível em: <http://rccs.revues. org/3666 >. Acesso em: 30 ago 2015, p. 30.

42. HOLTZ-BACHA, Christina. Politikerinnen - Bilder im internationalen Vergleich, p. 3-5.

43. NIEDERMAYER, Oskar. Anteil der Frauen an den Parteimitgliedschaften. BUNDESZENTRALE FÜR POLITISCHE BILDUNG. Dossier: Parteien in Deutschland. Disponível em: <http://www.bpb. de/politik/grundfragen/parteien-in-deutschland/140358/anteil-frauen>. Acesso em: 28 ago. 2015. 
O interesse na participação nos partidos cresce à medida em que as cotas também são aplicadas em seu âmbito interno. Fato é que a mera previsão da presença feminina nos órgãos e decisões partidários não necessariamente corresponderia na prática a um aumento das mulheres que fazem politica partidária; tal resultado depende diretamente da democracia intrapartidária.

Em uma perspectiva geral, há quem afirme que as cotas femininas não dependeriam de uma forte democracia interna nos partidos, que elas só estariam maquiando os verdadeiros problemas de gênero e possibilitando a manutenção do status quo, uma vez que não retirariam dos partidos as prerrogativas de decidirem sobre as candidaturas. ${ }^{44}$ Nesse sentido, caso se queira democratizar ao máximo o processo de candidaturas, com a adoção, por exemplo, de primárias abertas, seria mais difícil a adoção das cotas, uma vez que o controle dos partidos sobre a nomeação se enfraqueceria ${ }^{45}$ Para Óscar Sánchez Muñoz, entretanto, buscar uma democracia paritária nos partidos seria mitigar o princípio de liberdade de apresentação de candidaturas em prol da promoção de preceitos constitucionais, o que estaria diretamente ligado a democracia interna, vez que faria parte da elaboração de requisitos democráticos para o procedimento de candidaturas as políticas afirmativas femininas. ${ }^{46} \mathrm{~A}$ opção pela adoção das quotas, pois, deve levar em consideração essa escolha com relação à influência do partido no processo de candidaturas; assim, uma vez adotada, haveria a demanda ainda maior para um relacionamento democrático no seu interior.

A presença de uma democracia intrapartidária se revela como um importante mecanismo para combater os interesses pessoais e corporativistas no interior dos partidos. Ela se demonstra essencial, sobretudo, nos momentos de tomada de decisão, a qual deve ser realizada em verticalidade ascendente, submetendo órgãos executivos a convenções e assembleias partidárias. Tal democracia serve como base para a prevalência dos direitos dos filiados no partido, como, por exemplo, o de participação nas convenções e nos órgãos partidários, garantia de alterações periódicas dos cargos de direção do partido e direito de ampla defesa no caso de aplicação de eventuais sanções. ${ }^{47}$

Desempenhando os partidos políticos importante papel em vários Estados, não há como negar que o desenvolvimento de um governo democrático dependerá do quão democráticos eles são. ${ }^{48}$ Segundo Óscar Sánchez Munhoz, essa democracia intrapartidária se conectaria diretamente com o princípio de liberdade de acesso à competição eleitoral, uma vez que ela influenciaria diretamente nos procedimentos internos de seleção dos candidatos ${ }^{49}$ Democracia também pressupóe alternância no poder, que deve se dar em todas as instâncias, começando pelo próprio partido político, cuja organização interna deve garantir a participação de todos

44. BALDEZ, Lisa. The Pros and Cons of Gender Quota Laws: What Happens When You Kick Men Out and Let Women In?, p. 103.

45. KROOK, Mona Lena. Gender Quotas, Norms, and Politics, p. 116.

46. SÁNCHEZ MUÑOZ, Óscar. La igualdad de oportunidades en las competiciones electorales. Madrid: Centro de Estudios Políticos y Constitucionales, 2007, p. 154-157.

47. MEZZAROBA, Orides. Introdução ao Direito partidário brasileiro. Rio de Janeiro: Lumen Juris, 2003, p. 182.

48. SALGADO, Eneida Desiree. PÉREZ HUALDE, Alejandro. A democracia interna dos partidos politicos como premissa da autenticidade democrática. A\&C - Revista de Direito Administrativo \& Constitucional, Belo Horizonte, ano 15, n. 60, p. 63-83, abr./jun. 2015, p. 69.

49. SÁNCHEZ MUÑZZ, Óscar. La igualdad de oportunidades en las competiciones electorales, p. 134. 
e a ausência do monopólio do poder na mão de alguns poucos dirigentes. Assegurar certos direitos sob a existência de uma democracia intrapartidária não significaria acabar com a autonomia dos partidos, mas sim mitigá-la em favor de garantias e princípios constitucionais, os quais devem estar presentes nos estatutos partidários. ${ }^{50}$

Isso acontece na Alemanha, país em que a democracia intrapartidária é prevista diretamente na Constituição (artigo 21), a ser expressa no que diz respeito, principalmente, à origem e aplicação de seus recursos e à prestação pública de contas. ${ }^{51}$ Há entendimento doutrinário, ainda, que afirma ser essa democracia intrapartidária necessária e exigida não só por essa menção expressa, mas também, através de uma interpretação uniforme da Constituição, como garantia da colaboração dos partidos nos processos de formação de vontade democrática no Estado, exigência e pressuposto básico de um Estado democrático de Direito. ${ }^{52}$ Ressalta-se que o Estado democrático e social é considerado cláusula imutável, segundo a Constituição alemã (interpretação do art. 79(3), juntamente com o art. 20). Da mesma forma, observa-se que os partidos políticos ganharam importância e proteção constitucional, algo não observado anteriormente na história constitucional deste país. ${ }^{53}$

$\mathrm{Na}$ história político-partidária alemã se evidencia um período de exceção de direitos fundamentais, resultando na suspensão do funcionamento normal dos partidos. Foi durante o período do Nacional Socialismo na Alemanha, no governo de Hitler (em 1933), que se instituiu lei a qual proibiu a criação de novos partidos e instituiu o partido nazista como o único do país. ${ }^{54}$ Não obstante esse passado mais obscuro, a resposta dada ao tratamento dos partidos na fase de democratização não foi a liberdade total, mas justamente a sua regulamentação visando a garantia da democracia, na forma de uma autonomia mitigada, como aqui já citado.

Com base na lei dos partidos políticos (Parteiengesetz) é possível depreender algumas condições básicas para se atingir a democracia interna nos partidos. Há de se ter (i) uma organização vertical, cujas decisões sejam tomadas de baixo para cima; (ii) uma estrutura funcional, com divisão dos poderes e responsividade dos diretores perante os filiados; (iii) uma estrutura regional, com a possibilidade de divisão de competências entre as seccionais regionais subordinadas; e (iv) observância dos direitos dos filiados, tais como tratamento igualitário, igual poder de voto, liberdade de expressão e proteção contra expulsão arbitrária - segundo a lei dos partidos, as expulsões devem ser fundamentadas por escrito, após a realização de um processo em tribunal arbitral. ${ }^{55}$

50. SALGADO, Eneida Desiree. PÉREZ HUALDE, Alejandro. A democracia interna dos partidos politicos como premissa da autenticidade democrática, p. 77-79.

51. Artikel 21, Grundgesetz

(1) Die Parteien wirken bei der politischen Willensbildung des Volkes mit. Ihre Gründung ist frei. Ihre innere Ordnung muß demokratischen Grundsätzen entsprechen. Sie müssen über die Herkunft und Verwendung ihrer Mittel sowie über ihr Vermögen öffentlich Rechenschaft geben.

52. ALEMANN, Ulrich von; ERBENTRAUT, Philipp; WALTHER, Jens. Das Parteiensystem der Bundesrepublik Deutschland, p. 158.

53. RUDZIO, Wolfgang. Das politische System der Bundesrepublik Deutschland, p. 50.

54. ALEMANN, Ulrich von; ERBENTRAUT, Philipp; WALTHER, Jens. Das Parteiensystem der Bundesrepublik Deutschland, p. 44/45.

55. ALEMANN, Ulrich von; ERBENTRAUT, Philipp; WALTHER, Jens. Das Parteiensystem der Bundesrepublik Deutschland, p. 159. 
No Brasil, diferentemente da Alemanha, não há uma manifestação legislativa expressa sobre os direitos dos filiados e condições para uma democracia intrapartidária; mais precisamente, não há manifestação na Constituição com relação a ela. Constitucionalmente determina-se a autonomia partidária em definir seu modo próprio de organização interna e funcionamento, e a Lei dos Partidos Políticos traz mais algumas exigências, mas ainda sem estipular sobre a participação de filiados na escolha de dirigentes, ou sobre a forma de seleção dos candidatos. ${ }^{56}$

Dessa forma, constata-se que a realidade brasileira ainda pode avançar quando o assunto é democracia interna nos partidos. A aplicação de cotas de gênero no âmbito nacional não tem se demonstrado eficaz, e um dos motivos para tanto, dentre outros, pode vir a ser esse déficit democrático que se encontra na seleção dos candidatos e nos direitos dos filiados. Diante da realidade alemã, observa-se que é possível se ter uma iniciativa transformadora da sociedade, com a afirmação de direitos femininos, que parta da própria sociedade civil, mais especificamente dos partidos políticos; contudo, é evidente que esses ditames não conseguiriam ser efetivados se não estivessem baseados em uma premissa de organização democrática.

A partir dessa introdução à realidade política alemã das cotas fica evidente que o fomento à participação das mulheres na política não dá frutos imediatos. Já se passaram mais de 30 anos desde a instauração das primeiras cotas na Alemanha, e o país ainda procura ampliar o espaço feminino, seja na sociedade, na economia ou na política. A mudança vem sendo paulatina, mas já mostra alguns bons resultados, como o aumento de mulheres filiadas, ou mesmo partidos cujo o maior número de parlamentares é de mulheres. Sem dúvidas que nesse percurso visando a inclusão feminina, a democracia intrapartidária desempenhou um importante papel. E é nesse sentido que poderia haver uma das primeiras mudanças brasileiras: na promoção da democracia em todas as instâncias do sistema político, inclusive dentro dos partidos. Alterando sua política de cotas atual, ou não, o país ainda teria muito a ganhar com a democracia intrapartidária, pois ela por si só tende a alterar o status quo eleitoral de concentração de poderes e possibilitar uma participação maior das mulheres na política.

\section{Referências}

ALEMANN, Ulrich von; ERBENTRAUT, Philipp; WALTHER, Jens. Das Parteiensystem der Bundesrepublik Deutschland. Wiesbaden: VS Verlag, 2010.

BALDEZ, Lisa. The Pros and Cons of Gender Quota Laws: What Happens When You Kick Men Out and Let Women In? In: Politics \& Gender, 2 (2006), pp. 102-109. Disponível em: < http://dx.doi.org/10.1017/ S1743923X06221019>. Acesso em: 31 ago. 2015.

56. MEZZAROBA, Orides. Introdução ao Direito partidário brasileiro. Rio de Janeiro: Lumen Juris, 2003, p. 274; SALGADO, Eneida Desiree. PÉREZ HUALDE, Alejandro. A democracia interna dos partidos politicos como premissa da autenticidade democrática, p. 76. 
BUNDESZENTRALE FÜR POLITISCHE BILDUNG. Frauen auf dem Arbeitsmarkt der EU. Disponível em: < http://www.bpb.de/politik/hintergrund-aktuel1/202187/ frauen-auf-dem-arbeitsmarkt>. Acesso em: 28 ago. 2015.

CIA. The World Fact Book. Disponível em: <https://www.cia.gov/library/publications/ resources/the-world-factbook/geos/gm.html>. Acesso em: 28 ago. 2015.

DAHLERUP, Drude. What are the Effects of Electoral Gender Quotas? From studies of quota discourses to research on quota effects. Disponível em: $<$ http://paperroom.ipsa. org/app/webroot/papers/paper_5301.pdf>. Acesso em: 31 ago. 2015.

DER BUNDESWAHLLEITER. Gewählte nach Parteien. Disponível em: < http://www. bundeswahlleiter.de/de/bundestagswahlen/BTW_BUND_13/ergebnisse/gewaehlte/ partei/>. Acesso em: 28 ago 2015.

HOECKER, Beate. Frauen in der Politik. In: BUNDESZENTRALE FÜR POLITISCHE BILDUNG. Dossier: Frauen in Deutschland. Disponível em: <http://www.bpb. de/gesellschaft/gender/frauen-in-deutschland/49362/frauen-in-der-politik>. Acesso em: 28 ago. 2015.

HOFMEISTER, Heather; Hünefeld, Lena. Frauen in Führungspositionen. In: BUNDESZENTRALE FÜR POLITISCHE BILDUNG. Dossier: Frauen in Deutschland. Disponível em: < http://www.bpb.de/gesellschaft/gender/frauen-in-deutschland/49400/ fuehrungspositionen>. Acesso em: 28 ago. 2015.

HOLTZ-BACHA, Christina. Politikerinnen - Bilder im internationalen Vergleich. In: APuZ - Aus Politik und Zeitgeschichte. Frauen in Politik und Medien. Disponível em: $<\quad$ http://www.bpb.de/shop/zeitschriften/apuz/31540/frauen-in-politik-und-medien>. Acesso em: 28 ago. 2015.

INTER-PARLIAMENTARY UNION. GERMANY: Bundesrat (Federal Council). Disponível em: <http://www.ipu.org/parline-e/reports/2122_A.htm>. Acesso em: 30 ago. 2015.

INTER-PARLIAMENTARY UNION. GERMANY: Deutscher Bundestag (German Bundestag). Disponível em: <http://www.ipu.org/parline-e/reports/2121_A.htm>. Acesso em: 30 ago. 2015.

INTER-PARLIAMENTARY UNION. Women in national parliaments. Disponível em: $<$ http://www.ipu.org/wmn-e/classif.htm>. Acesso em: 30 ago 2015.

INSTITUTE FOR DEMOCRACY AND ELECTORAL ASSISTENCE. Voter turnout data for Germany. Disponivel em: < http://www.idea.int/vt/countryview.cfm?CountryCode $=$ DE $>$. Acesso em: 30 ago. 2015. 
KROOK, Mona Lena. GenderQuotas, Norms, and Politics. In: Politics \& Gender, 2 (2006), pp. 110—118. Disponível em: < http://dx.doi.org/10.1017/S1743923X06231015>. Acesso em: 31 ago 2015.

KÜSCHNER, Isabelle. Frauen in den Parteien. In: APuZ - Aus Politik und Zeitgeschichte. Frauen in Politik und Medien. Disponível em: < http://www.bpb.de/shop/zeitschriften/apuz/31540/frauen-in-politik-und-medien>. Acesso em: 28 ago. 2015.

MANIN, Bernard. La democracia de los modernos: los principios del gobierno representativo. Disponível em: <http://webcache.googleusercontent.com/search? $\mathrm{q}=$ cache:CAYbExB3d9YJ:www.hacienda.go.cr/centro/datos/Articulo/La\%2520 democracia\%2520de\%25201os\%2520modernos. $\mathrm{doc}+\& \mathrm{~cd}=1 \& \mathrm{hl}=\mathrm{fr} \& \mathrm{ct}=\mathrm{clnk} \& \mathrm{gl}=\mathrm{br}>$. Acesso em: 10 mai 2015.

MEYER, Birgit. "Nacht, wenn der Generalsekretär weint" - Politikerinnen in der Presse. In: APuZ - Aus Politik und Zeitgeschichte. Frauen in Politik und Medien. Disponível em: < http://www.bpb.de/shop/zeitschriften/apuz/31540/frauen-in-politik-und-medien>. Acesso em: 28 ago. 2015.

MEZZAROBA, Orides. Introdução ao Direito partidário brasileiro. Rio de Janeiro: Lumen Juris, 2003.

MIGUEL, Luís Felipe. Impasses da Accountability: dilemas e alternativas da representação política. In: Revista Sociologia Política, Curitiba, n. 25, jun 2006.

NIEDERMAYER, Oskar. Anteil der Frauen an den Parteimitgliedschaften. BUNDESZENTRALE FÜR POLITISCHE BILDUNG. Dossier: Parteien in Deutschland. Disponível em: <http://www.bpb.de/politik/grundfragen/parteien-in-deutschland/140358/anteil-frauen>. Acesso em: 28 ago. 2015.

PATEMAN, Carole. Garantir a cidadania das mulheres: A indiferença e outros obstáculos. Tradução de Teresa Tavares. In: Revista Crítica de Ciências Sociais, n. 89, 2010. Disponível em: $<$ http://rccs.revues.org/3666>. Acesso em: 30 ago 2015.

PITKIN, Hanna Fenichel. Representação: Palavras, Instituições e Ideias. Disponível em: <http://www.scielo.br/pdf/ln/n67/a03n67.pdf>. Acesso em: 10 mai 2015.

POST, Robert. Democracy and Equality. Disponível em: < http://digitalcommons.law. yale.edu/fss_papers/177/>. Acesso em: 10 mai 2015.

QUOTA PROJECT. Germany. Disponível em: < http://www.quotaproject.org/uid/countryview.cfm?id=61>. Acesso em: 28 ago. 2015.

RUDZIO, Wolfgang. Das politische System der Bundesrepublik Deutschland. Wiesbaden: VS Verlag, 2011. 
SALGADO, Eneida Desiree. Representação política e o modelo democrático brasileiro. In: CLÈVE, Clèmerson Merlin (Coord.). Direito Constitucional Brasileiro, vol.1: Teoria da Constituição e Direitos Fundamentais. São Paulo: Revista dos Tribunais, 2014, p. $1089-1105$.

SALGADO, Eneida Desiree. PÉREZ HUALDE, Alejandro. A democracia interna dos partidos politicos como premissa da autenticidade democrática. $A \& C$-Revista de Direito Administrativo \& Constitucional, Belo Horizonte, ano 15, n. 60, p. 63-83, abr./jun. 2015.

SÁNCHEZ MUÑOZ, Óscar. La igualdad de oportunidades en las competiciones electorales. Madrid: Centro de Estudios Políticos y Constitucionales, 2007.

SPIEGEL ONLINE. Gleichberechtigung: Bundestag beschließt Frauenquote. Disponível em: < http://www.spiegel.de/politik/deutschland/deutscher-bundestag-beschliesst-frauenquote-a-1022093.html>. Acesso em: 28 ago. 2015.

XYDIAS, Christina. Women's Rights in Germany: Generations and Gender Quotas. In: Politics \& Gender, 10 (2014), 4-32. Disponível em: <http://dx.doi.org/10.1017/ S1743923X13000524>. Acesso em: 31 ago 2015.

YOUNG, Iris Marion. Inclusion and Democracy. Oxford: Oxford University Press, 2000. 
Recebido em: 10/11/2015

Aceito em: 30/11/2015

\section{Como citar}

CHAGAS, Carolina. As mulheres e a política na Alemanha: as cotas de gênero e a democracia interna partidária. Ballot. Rio de Janeiro: UERJ. Volume 1 Número 2 Setembro/Dezembro 2015. pp. 103-122. Disponível em: [http://www.e-publicacoes.uerj.br/index.php/ballot]

\section{(c) (1) (9)}

A Revista Ballot está licenciada sob uma licença Creative Commons Atribuição - Não Comercial - Compartilha Igual 3.0 Não Adaptada. 